\title{
Nuevos paradigmas educativos e inteligencias pedagógicas arquetípicas: reflexiones sobre el "corazón de la educación"
}

doi: $10.33264 /$ rpa.201901-10

\author{
Jorge Osorio Vargas \\ Profesor de la Escuela de Psicología, Universidad de Valparaíso. \\ Director del Observatorio de Educación de Personas Adultas, \\ Facultad de Ciencias de la Educación, Universidad de Playa Ancha. \\ ID: 0000-0001-9787-5599
}

\section{Resumen}

El presente texto propone ahondar en la noción del "corazón de la educación", concepto que tiene de raíz a la denominada pedagogía axial, métodos educativos que consideraban ejes como el lenguaje sapiencial poético, el desarrollo de las artes, la escritura y vida meditativa y que culminaban en una vía del conocimiento y del relato sapiencial. Esto, en directa contraposición a la pedagogía occidental moderna, que asume el mecanicismo, lo cognitivo y el utilitarismo liberal -ideas basadas en resultados-, y que terminan imponiéndose en la enseñanza contemporánea.

Finalmente, se plantean una serie de lineamientos para volver a instaurar a la pedagogía axial como movimiento cultural. Este programa consiste en: la problematización de los actuales paradigmas educativos de la formación instrumental, la exploración de una epistemología fundada en la contradicción y el desarrollo de nuevas ideas pedagógicas basadas en una dialógica liberadora, entre otras.

Palabras clave: educación, pedagogía axial, pedagogía, pensamiento freireano, Paulo Freire, paradigmas educativos.

\section{Abstract}

The present text proposes delving into the notion of the "heart of education", a concept that is rooted in the so-called axial pedagogy, educational methods that took into consideration axes such as poetic wisdom language, the development of the arts, writing and meditative life, and that culminated in a path of knowledge and wisdom story. This, in direct contrast to modern western pedagogy, which assumes the mechanistic, cognitive and liberal utilitarianism - results-based ideas - that end up imposing on contemporary teaching.

Finally, a series of guidelines are proposed to re-establish axial pedagogy as a cultural movement. This program consists of making the current educational paradigms of instrumental training problematic, the exploration of an epistemology based on 
contradiction, and the development of new pedagogical ideas based on a liberating dialogism, among others.

Keywords: education, axial pedagogy, pedagogy, Freirean thinking, Paulo Freire, educational paradigms.

Este texto sobre el "corazón de la educación" es una expresión de lo que he llamado la pedagogía de lo "próximo-complejo, que pretende ser una síntesis participativa (o vivida) de mi experiencia educativa y de mis búsquedas espirituales, pedagógicas y políticas. $Y$ es un desafío relevante que lo intente en un tiempo socialmente altisonante para referirse a los necesarios cambios educacionales que permitan superar las visiones tecno-liberales y las llamadas "progresistas" que convergen cada una por su propia vía en declarar el proyecto de la "sociedad de oportunidades" y su visión de la educación como trampolín de la movilidad social". Ambas versiones del cambio educativo licúan el sentido axial de las manifestaciones ciudadanas globales que procuran una sociedad democrática y justa donde la educación sea como generadora de capacidades humanas cognitivas, sociales, cívicas, políticas y emocionales que empoderen los sujetos y sus comunidades para avanzar en sociedades que distribuyan socialmente el poder y produzcan un "giro participativo" en la democracia ${ }^{24}$

La reflexión parte por el título de la convocatoria: se trata de hablar del corazón de la educación. Y para ello trazo un camino que va desde el sentido que la tradición sapiencial le da al "corazón" de las cosas hasta las formas que debiera adquirir una educación integradora tanto de las dinámicas de los asombros y conocimientos personales como de las exigencias de trabajar para un mundo justo y solidario.

Por lo general, la epistemología occidental valida sólo (o preferentemente) la razón instrumental, que se nutre del método científico mecanicista, como la vía para referirse al mundo "objetivo" de las relaciones sociales y de las formas que las sociedades tiene para "educarse". Yo deseo caminar otra vía: la vía del conocimiento y del relato sapiencial, que sabemos que, desde la época de los grandes sabios que Jaspers Ilamó la "era axial", han sido otras formas de referirse al "corazón" de la vida en todas sus dimensiones y que ha tenido formas escriturales simbólicas, arcanas, arquetípicas, litúrgicas, poéticas, pictóricas por sobre la escritura de lo "verdadero" y de lo "objetivo" al modo como lo ha conocido el mundo occidental, desde los albores de la investigación científica "basada en evidencias y resultados" en la temprana modernidad.

Mi visión se nutre del punto de partida del "pensamiento débil" de que renuncia a construir ontológicamente grandes y pesados relatos sobre el ser, adoptando una

\footnotetext{
${ }^{24}$ Rosanvallon, Pierre (2007). La Contra democracia, Manantial, Buenos Aires
} 
postura de "escucha" y hermenéutica del sentido del "educar", desde la presencia, la contingencia y la-vida-vivida-con-otros en contextos poli-éticos concretos, en cuales pretendemos actuar cordialmente, desde el cuidado, la reciprocidad y el respeto a la diversidad.

Esta manera de confrontar las culturas y sus las maneras de "educarse" (que en sentido estricto - educere - podríamos llamar también las maneras "de "salir fuera", de "liberarse") conlleva una crítica a las referencias epistémicas de la pedagogía instrumental tecno-liberal y se identifica con el movimiento cultural de la educación liberadora latinoamericana (dialógica, crítica y transformadora) inspirada en el pensamiento de Paulo Freire. Pero también esta crítica pedagógica implica una crítica política y una "puesta en obra" de movimientos ciudadanos y pedagógicos capaces de desarrollar sus propios relatos sobre "el corazón de la educación", y cuya dimensión axial se expresa en la no-violencia activa, el ecologismo político y el feminismo cultural.

En los textos bíblicos y en los escritos espirituales del paleo cristianismo el corazón es el lugar de la vida humana, de los sentidos profundos que nos animan a amar, conocer, vivir con otros. En la tradición mística cristiano-oriental el corazón es el lugar de la relación yo-Tú, la relación con la trascendencia. El “centro", el "misterio", la "sede" de de la conciencia humana y de su "estar en el mundo". Por lo mismo, se lo considera la sede de origen de la creación, del pensamiento, del estar-en-obra de los seres humanos, de sus sentimientos, de la sanación y de la integración de la vida interior tensada por el amor

En el lenguaje místico el corazón es el ser, del misterio del ser. Corazón y misterio pueden expresar lo mismo: son la manera de llamar las energías primarias y constituyentes de la vida, la fuente y sentido de lo que "estamos siendo". Para la mística esa energía es el amor y su lenguaje siempre será sapiencial y a él se accede y conjuga a través de una presencia contemplativa en el mundo ${ }^{25}$.

Estamos entonces en un doble plano en este texto: por una parte nos referimos al corazón de "algo" en sentido metafórico, pero también desde la lógica del lenguaje sapiencial. El lenguaje sapiencial es algo más que una forma de decir, es la expresión de un experiencia participativa ( "vivida" como acontecimiento) que no se desarrolla sobre la base de "pruebas", "datos" “ evidencias” según el esquema científico de la modernidad occidental sino de categorías fenomenológicas “débiles”, y que han sido

25 Sobre la espiritualidad y el lenguaje místico del corazón ver: Maloney, George (2008) La Oración del Corazón. La tradición contemplativa del Oriente Cristiano, Sal Terrae, Santander 
marginadas por las epistemologías dominantes ${ }^{26}$. Sus vías de conocimiento son comtemplativas, estéticas, poéticas, imaginales, y también las que se manifiestan desde lo que algunos al llamado la "metafísica de la presencia", es decir, de la "proximidad" o, dicho de otro modo, desde el ámbito o praxis radical del "buen samaritano", que en la actualidad da el sentido las "éticas de cuidado" que animan los nuevos movimientos sociales (como el feminista y el eco-político). ${ }^{27}$

Hablar del “corazón de la educación” desde estos “márgenes” supone reconocer:

- La experiencia participativa y vivida

- La apertura a lecturas y descubrimientos de signos , "rostros" y "huellas" de la "creatividad radical" del corazón, o del misterio o de las fuentes del sentido de la vida que se expresan en práctica dialógica de la educación

- La búsqueda de lenguajes de mediación entre la metafísica de la presencia, la cualidad de la proximidad ( y sus huellas) y la educación como "cuidado"

La epistemología y la pedagogía occidental moderna se distanciaron de estas exploraciones cuando asumieron como soporte el instrumental racio-céntrico y mecanicista y pretendieron modernizar la educación según el utilitarismo liberal configurándose un pensamiento sobre la educación centrada en lo "cognitivo" y en los "resultados".

Esta "modernidad educativa" sepultó el núcleo del pensamiento y de la sabiduría de la época axial (la época de Sócrates, Buda Confucio, Jeremías) ${ }^{28}$, que había puesto los cimientos que lo que hasta hoy identificamos como la más originaria matriz del “sentido de la vida" y de una “inteligencia pedagógica arquetípica” cuyos ejes son:

- El desarrollo del lenguaje sapiencial y poético para manifestar el sentido personal y social de la vida, de la relación con la naturaleza y con la polis.

- El desarrollo del "saber preguntar" sobre el sentido, el misterio y de las fuentes del todo.

- El desarrollo de las artes prácticas para comunicarse, organizar la vida social y el auto-conocimiento a través de "escuelas" orientadas a la religación de los interno y lo externo, lo individual y familiar, lo contingente y lo trascendente,

\footnotetext{
${ }^{26}$ Sobre el llamado "giro participativo" para estudiar y valorar la “espiritualidad” ver: Ferrer, Jorge y Sherman, Jacob ( editores) (2011) El Giro Participativo, Kairós, Barcelona

${ }^{27}$ En su Ética de la Razón Cordial (2007), Adela Cortina sostiene que dos los sustentos de una educación en la ciudadanía del siglo XXI: justicia y gratuidad (Editorial Nobel). Es preciso que profundicemos en principios pedagógicos claves como son la reciprocidad, la mutualidad, el cuidado y la proximidad como actitudes "fuertes" del aprendizaje necesario para "vivir-junto-aotros-as"

${ }^{28}$ Sobre el pensamiento sapiencial de la época llamada por Karl Jaspers “época axial” ver: Armstrong, Karen, (2007) La Gran Transformación, Paidós, Barcelona
} 
lo instrumental y lo lúdico, lo escrito y lo oral, la memoria y el olvido, lo magistral y lo "en formación".

- La compasión y de la proximidad "con la viuda y los huérfanos", los desplazados, oprimidos y desechados como valores irrenunciables.

- El desarrollo de la contemplación, la vida meditativa y el diálogo socrático como "competencias" claves para el desarrollo humano.

- El desarrollo del arte y la escritura como experiencia tanto de creatividad y potencia, como de fragilidad y minimalismo.

Esta "pedagogía axial" (próxima-compleja) se entiende como un oficio artesanía29: se trata de dar forma a un "espacio interior", a la manera de quien organiza un "espacio para habitar", para "morar". En la pedagogía axial forma y contenido "habitan", y entre ellas hay reciprocidad, lenguaje común, pues son manifestaciones del mismo fenómeno. La fuente que anima esta pedagogía es el "deseo "de saber" y de "participar" de las posibilidad del ser. No se trata de un saber letrado, sino de un saber de sabiduría. 30

Será un desafío importante para nuestro proyecto profundizar en este sustento histórico para releer con claves contemporáneas asuntos que han quedado oscurecidos por la pedagogía moderna-instrumental como son: la tensión política de la escatología y el discurso de la trascendencia, la educación como configuración de una praxis rebelde nutrida desde las "escrituras" del corazón, la pobreza y la cultura popular en cuanto espacios de educación liberadora, la acción formadora de los-as docentes como acción poética-política que conjunta el pensamiento, la escritura y la "fundación" alternativa de espacios y redes políticas y espirituales, valorándose movimientos sociales sub-alternos y "situaciones marginales" como espacios educativos críticos, como son los márgenes de las ciudades, el hábitat de los enfermos, de los desechables, de los disidentes, de los exiliados, de los discriminados.

En este punto me asocio a una tendencia de análisis que revaloriza la tradición sapiencial crítica y rebelde (desde el "corazón") de pensadores y reformadores que en el mundo occidental bebe de las fuentes del kinismo de Diógenes en sus paleoantecedentes hasta los actuales movimientos ecologistas y alter-mundistas. ${ }^{31}$ Tanto

\footnotetext{
${ }^{29}$ Véase el concepto del "buen artesano" como imagen del buen educador-a en Sennet, Richard (2009)

El Artesano, Anagrama, Barcelona.

$3^{30}$ Los griegos le llamaron paideia y lo asociaban con la virtud en la esfera pública.

${ }^{31}$ Ver: Cuesta, José Alberto (2011) Ecocinismos. La crisis ecológica desde la perspectiva de la filosofía cínica, Biblioteca Buridán; también : Foucault, Michel (2010) El Coraje de la Verdad , FCE, México
} 
en pedagogía como en política la estrategia kinica resulta ser una forma muy expresiva de lo que queremos plantear: mordacidad, desvergüenza, parresia (amor a la verdad y expresión con vigor), subversión del mercantilismo, no-violencia radical, critica a la sociedad de consumo, organización de minorías abrahámicas ${ }^{32}$.

Si queremos hacer de esta pedagogía axial ("eco-reflexiva", "próxima-compleja”33) un movimiento cultural, una convocatoria activa a cambiar nuestros modos de educar, a renovar las escuelas y a generar educadores rebeldes y reformadores debemos plantear un programa, que me permito describir de esta manera:

- Integrar las aspiraciones de "verdad" e "integralidad" aisladas en múltiples experiencias educativas en una red de pensamiento capaz de comunicar "sentidos" y aspiraciones a construir estrategias sapienciales para educar y formar sujetos y comunidades

- Problematizar la "ética" instrumental de los "buenos resultados" de la pedagogía dominante en vista de una "ética cordial” que entienda la educación como un proceso de gratuidad, como una experiencia de don, como un hábito del corazón que aceita las redes de la rebelión y la justicia 34

- Indagar la complejidad del "estar siendo humano-as", del "habitar" y de la "polis" re-alfabetizando la "docencia" y la "resistencia" para olvidarnos de fundamentos y sólidas arquitecturas y explorar la fuerza del pensamiento complejo, de una epistemología basada en la contradicción, - fisura de lo cierto y lo incierto-, - de lo próximo y lo complejo.

- Desarrollar la dialógica liberadora y participativa del "enseñar" , con el sustento de las experiencias freireanas, de la educación popular, de las pedagogía crítica y descolonizadoras: la comunitarización del aprendizaje, la formas participativas de amplificación hermenéutica de las experiencias de disidencias, rebeldía y vivencia de los márgenes, "hablando" todas la "lenguas" y explorando todas las inteligencias y sus escrituras ( poéticas, sapienciales, imaginales, corporales, estéticas)

\footnotetext{
${ }^{32}$ La expresión es de Lanza del Vasto refiriéndose a los movimientos no-violentos rebeldes que en siglo XX realizaban procesos de liberación y lucha por la justicia en diversos ámbitos del mundo, siendo los más paradigmáticos el movimiento gandhiano y el de los derechos civiles de Martin Luther King

33 Osorio, Jorge (s/d) Lo Próximo-Complejo. El enfoque eco-reflexivo en educación y política ciudadana (Impreso en obra por la Editorial de la Universidad Bolivariana de Santiago de Chile, disponible de forma gratuita en la web)

${ }^{34}$ Bellah, Robert (1989) Hábitos del Corazón, Alianza, Madrid.
} 
- Desarrollar el sentido práxico que potencie el desarrollo humano integrador del pensamiento y la acción, que reconozca como condición humana la necesaria politicidad de las relaciones sociales, esto es la organización de lo "común" y lo "público", llevando al ámbito de lo político la ética cordial del cuidado, de la no- discriminación, de la "proximidad-prioridad del samaritano".

\section{Referencias}

Armstrong, K. (2007). La gran transformación. Barcelona: Paidós.

Bellah, R. (1989). Hábitos del Corazón. Madrid: Alianza.

Cortina, A. (2007). Ética de la Razón Cordial: Educar en la ciudadanía del Siglo XXI. Ediciones Nóbel.

Cuesta, J. (2011). Ecocinismos. La crisis ecológica desde la perspectiva de la filosofía cínica. Biblioteca Buridán.

Ferrer, J. \& Sherman, J. (ed.) (2011). El Giro Participativo. Barcelona: Kairós.

Foucault, M. (2010). El Coraje de la Verdad. México: Fondo de Cultura Económica.

Maloney, G. (2008). La Oración del Corazón: La tradición contemplativa del Oriente Cristiano. Santander: Sal Terrae.

Osorio, J. (2009). Lo Próximo-Complejo. El enfoque eco-reflexivo en educación y política ciudadana. Santiago: Ediciones Universidad Bolivariana.

Rosanvallon, P. (2007). La Contra democracia. Buenos Aires: Manantial.

Sennet, R. (2009). El Artesano. Barcelona, Anagrama.

\begin{tabular}{l}
\hline Jorge Osorio Vargas \\
Doctorando en Educación en la Universidad La Salle, Costa Rica. Educador e historiador chileno. \\
Licenciado en Historia de la Universidad Católica de Valparaíso. Diplomado de Post Graduación \\
del Programa de Desarrollo y Derechos Humanos del Institute of Social Studies (ISS), La Haya. \\
Especialista en Investigación- Acción y Educación de Personas Adultas. Profesor de la Escuela de \\
Psicología y del Magister de Educación para la Inclusión, Diversidad e Interculturalidad de la \\
Universidad de Valparaíso. Director del Observatorio de Educación de Personas Adultas, Facultad \\
de Ciencias de la Educación, Universidad de Playa Ancha. ORCID ID: 0000-0001-9787-5599. \\
Email: josorio.humanidades@gmail.com
\end{tabular} 